\title{
Research on the Learning Willingness of Engineering College Students in SPOC Flipped Class
}

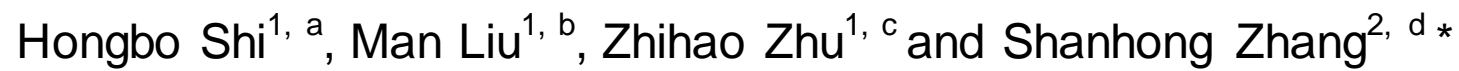 \\ ${ }^{1}$ School of Economics and Management, Harbin Institute of Technology, Weihai 264209, China; \\ 2 The Second Affiliated Hospital, Dalian Medical University, Dalian 116023, China. \\ arand@sina.com, bliuman792499791@163.com, 'czh3514@hotmail.com, d*shiffer@sina.com
}

Keywords: SPOC; Flipped class; Willingness to learn; Influencing factors

\begin{abstract}
MOOC has developed rapidly since 2012. However, SPOC has subsequently emerged and ensured the quality of teaching due to some deficiencies of MOOC. Additionally, it has a good application prospect with the help of flipped class and the combination of online and offline methods. In this study, a questionnaire survey is conducted to investigate the learning willingness in SPOC flipped class of the undergraduate in an engineering university. The results show that students have a strong willingness to SPOC flipped class learning, and this method can give more autonomy to learning and improving their own learning interests and effectiveness. A variance analysis of students' gender, grades and other attributes propose that students' gender and grade have no obvious influence on the willingness to SPOC flipped classes learning. The students who have better grades and experience in self-motivated MOOC are more supportive of SPOC flipped classes. Based on the survey results, several suggestions from four levels were puts forward to provide reference for the development and promotion of SPOC flipped class teaching pilots.
\end{abstract}

\section{Introduction}

In 2012, it was known as the first year of the Massive Open Online Course [1]. Since then, the MOOC was once considered to be the main education model in the future. With the increase of its popularity, its defects have gradually appeared. MOOC has problems such as low assessment difficulty and integrity of the test [2]. Especially for engineering majors, the content of the course lacks experimental and practical links. Therefore, society and universities do not recognize the quality of MOOC education, not to mention replacing the traditional university teaching model. At present, the education sector has gradually shifted to the combination of SPOC (Small Private Online Course) and flipped class [3]. SPOC model makes a teacher play a guiding role effectively and increase participation and mastery of knowledge of students [4]. Many universities at home and abroad try to open the SPOC flipped class model on campus for teaching practice, such as the University of California-Berkeley, Massachusetts Institute of Technology, Harvard University, Tsinghua University, Zhejiang University, etc. Compared with the MOOC teaching practice effect, the SPOC flipped class Teaching has a significant effect in improving students' interest in learning and achievement [5].

The study of SPOC flipped class focuses on the design and practice of teaching model. However, the evaluation of teaching experiments is mainly conducted from the comparison of results, while there is little research on the feedback of the students who finished the course, and there is almost no research on learning willingness of the students who first learn at SPOC flipped class. This article aims to investigate and research the learning willingness of the college students to learn about SPOC flipped class, which helps to understand the learning willingness of tens of millions of college students using this teaching model. It is specifically designed to effectively promote the SPOC flipped class so that students and teachers are satisfied with the teaching effect. 


\section{Method}

\subsection{Sample collection}

This study design a questionnaire based on the theoretical basis of SPOC flipped class literature at home and abroad, combining the opinions of SPOC teaching teachers and engineering college students. Using the Likert 5-point scale, engineering university undergraduate students were selected as the study object, and data was collected through a questionnaire survey. After the first draft of the questionnaire was formed, 30 students were selected for pre-survey and in-depth interviews. According to the pre-survey and interview results, the content of the questionnaire was further revised and improved, and a questionnaire was finally formed. The questionnaire was divided into five parts: initial language, basic situation, possible problems in current learning, SPOC research, willingness and attitude.

\subsection{Descriptive Statistical Analysis}

In this survey, 200 counselors were contacted by professional heads to issue 200 questionnaires. According to the completeness of questionnaires, the regularity of answers, and the effectiveness of pairing, 161 valid questionnaires were obtained, with an effective rate of $80.5 \%$. Among them, $79.5 \%$ were males and $20.5 \%$ are females, which was in line with the gender ratio of the engineering colleges; the freshmen, sophomores, juniors and seniors accounted for $21.7 \%, 26.1 \%, 18 \%, 34.2 \%$; from the score distribution point of view, the largest number is 70 points to 80 points, accounting for $47.2 \%$ of the total sample; 80 points to 85 points accounted for 26.7\%; 60 points to 70 points accounted for $16.1 \%$ in line with the normal distribution of results. About $36.6 \%$ of the students completed MOOC except for the teaching program, reflecting the students' self-learning initiative and familiarity with online education.

\subsection{Statistical tools and methods}

This study uses SPSS22.0 statistical analysis software to analyze and process the data. Firstly, descriptive statistics are conducted on the collected data, and then the collected data are analyzed according to the analysis methods such as one-way ANOVA and independent sample T-test. Reliability is the reliability or stability of the scale. The consistency among the variables of the measured variable is acceptable when Cronbach's $\alpha>0.7$ [6]. From Table 1, it can be seen that the data reliability of the measurement scale of the questionnaire constructed in this study is acceptable.

Table 1 The reliability of each dimension

\begin{tabular}{|c|c|c|c|c|}
\hline Dimension & $\begin{array}{c}\text { Studying } \\
\text { problem }\end{array}$ & Teaching resources & Interaction and communication & Willingness and attitude \\
\hline Cronbach's $\alpha$ & 0.833 & 0.762 & 0.73 & 0.8 \\
\hline
\end{tabular}

\section{Data Analysis and Results}

\subsection{Student initiative}

Student initiative mainly investigates whether students are willing to master the initiative of learning, which is also the primary characteristic of SPOC flipped class. According to the survey, most students want to master the progress (mean value 3.42) and choose the time and place (mean value 3.60) by themselves. Freedom and the ability to learn at anytime, anywhere are also the advantages of SPOC flipped class.

\subsection{Course progress and assessment}

The traditional class has a unified teaching schedule. The assessment mainly relies on the final exam and the mode is single. For the SPOC flipped class, between each offline class, students can control the progress of their own learning, and assessment methods can be more diverse. This section finds that no counting of the total score leads to a reduction in students' self-consciousness in completing the assignment (mean 2.65). The middle assessment can effectively control the students' learning progress (mean 3.81). Although the SPOC flipped class model gives students a lot of freedom, it should still avoid the students leaving all learning tasks to the end, which also has a great impact on the offline curriculum practice. Whether the differences in learning progress will affect the individual's learning progress, the obtained mean value is 3.81, and the standard deviation is also small, indicating that the positive peer 
effect has a psychological supervision effect on learning willingness. On the other hand, about two-thirds of the students do not want other students to know their progress, and even half of the students hope that the progress of the study can be seen only by themselves, indicating that students are reluctant to open their minds about the progress of learning.

\subsection{Interaction and communication}

Online social networking has become a part of modern people's life. Whether or not, it is suitable for academic exchange via the Internet platform, a place where needs to be considered for SPOC flipped class. According to the survey, the atmosphere of the discussion area with insufficient activity will further inhibit individuals' willingness to communicate (mean 3.35); students will have higher willingness to ask questions and communicate on the online platform (mean 3.32). The vast majority of students are willing to answer questions raised by others in their own circumstances (mean 3.95 and small standard deviation). Most of the students think that they can communicate more easily with their teachers online (mean value is 3.95 and standard deviation is small), and the online platform can increase the willingness of students and teachers to communicate. Most of the students were positive about the online evaluation work (mean 3.44), but the larger standard deviation (0.872) also indicated that some students did not agree with this statement, and the effect still needs to be tested; it was considered by most of the students that face-to-face communication would be more effective (mean value 3.57). Therefore, it is more appropriate to concentrate on discussion about the problems that cannot be solved in the discussion forum during offline classes. This is also the place where the SPOC flipped class is more advantageous than pure MOOC.

\section{Exploratory Results Analysis}

\subsection{Study of will and attitude}

Questions I to V investigate the extent to which students eventually supported SPOC flipped class. The results are shown in Table 2.

Table 2 Descriptive statistical results of willingness and attitude

\begin{tabular}{|l|c|c|c|c|c|}
\hline & $\mathrm{N}$ & Minimum & Maximum & Average & Standard Deviation \\
\hline $\begin{array}{l}\text { I. If turning some of your classes into SPOC flipped } \\
\text { classes in the future, your attitude }\end{array}$ & 161 & 2 & 5 & 3.81 & .771 \\
\hline $\begin{array}{l}\text { II. In the mode of SPOC flipped class, I will learn on } \\
\text { schedule }\end{array}$ & 161 & 2 & 5 & 3.73 & .640 \\
\hline $\begin{array}{l}\text { III. The mode of SPOC flipped class make learning } \\
\text { interesting }\end{array}$ & 161 & 2 & 5 & 3.84 & .697 \\
\hline $\begin{array}{l}\text { IV. The mode of SPOC flipped class make learning } \\
\text { cumbersome }\end{array}$ & 161 & 2 & 5 & 3.45 & .741 \\
\hline $\begin{array}{l}\text { V. The mode of SPOC flipped class will increase } \\
\text { learning tasks }\end{array}$ & 161 & 1 & 5 & 3.17 & .700 \\
\hline List wise N & 161 & & & & \\
\hline
\end{tabular}

The mean value of each question in this section exceeds 3 , and it can be said that most students are positive about SPOC flipped class. Specifically, the degree of support for the SPOC flipped class is 3.81 with a high score and a minimum value of 2, indicating that there is no student who is very resistant of it, and it can be considered that the student is more supportive of the school's SPOC flipped class test. The second problem has an average value of 3.73 and a small standard deviation. It can be assumed that most students feel that they can follow the schedule. The average of the three-question title is 3.84, which means that most students think that the new model can make learning fun. Questions IV and V are reversed. The average result is greater than 3 , indicating that majority of students do not think that the SPOC flipped class mode will increase the workload or be cumbersome, but the average value is not high. Some students still hold a negative attitude. This section provides students with a preliminary prediction of the new model. However, the actual results will require further investigation after real learning. 
After a descriptive statistical analysis of the questionnaire results, we did a further analysis of the effect on the student's gender, grade level, achievement level, and whether or not there was an independent MOOC experience on the final learning intention, so that students can be taught according to their characteristics.

\subsection{Influence of gender on learning willingness in SPOC flipped class}

From Table 3, it can be concluded that there is no significant difference in the preferences of different genders for SPOC flipped class, but there is a significant difference in question II "In the mode of SPOC flipped class, I will learn on schedule”, indicating that girls learn more consciously. In support of the SPOC flipped class, the average male student is slightly higher than the female student, but the difference is not significant. Both male and female students believe that the SPOC flipped class model will make learning fun.

Table 3 T-test results of genders on learning willingness

\begin{tabular}{|c|c|c|c|c|}
\hline & \multicolumn{2}{|c|}{ Your gender (mean \pm standard deviation) } & \multirow{2}{*}{$\mathrm{t}$} & \multirow{2}{*}{$\mathrm{P}$} \\
\cline { 2 - 5 } & Male(N=128) & Female(N=33) & 0.92 & 0.36 \\
\hline I & $3.84 \pm 0.75$ & $3.70 \pm 0.85$ & -2.79 & $0.01^{* *}$ \\
\hline II & $3.66 \pm 0.63$ & $4.00 \pm 0.61$ & -0.09 & 0.93 \\
\hline III & $3.84 \pm 0.70$ & $3.85 \pm 0.71$ & -0.46 & 0.64 \\
\hline IV & $3.46 \pm 0.74$ & $3.39 \pm 0.75$ & 0.13 & 0.9 \\
\hline V & $3.16 \pm 0.67$ & $3.18 \pm 0.81$ & & \\
\hline
\end{tabular}

\subsection{Influence of grade on learning willingness in SPOC flipped class}

From Table 4, it can be found that the grade has no significant effect on the willingness of SPOC flipped class learning. Specifically, the degree of support in the lower grades is lower, and higher grades are higher. Younger students do not know enough about e-learning and are still accustomed to the traditional learning model. Self-study ability is still lacking. The senior students have improved their self-learning ability through the 3 to 4 years of university courses, and they have basically participated in MOOC learning in the teaching plan. They have a certain understanding of online education and have more support for the SPOC flipped class model.

Table 4 Variance analysis of learning willingness in different grades

\begin{tabular}{|c|c|c|c|c|c|c|}
\hline & \multicolumn{4}{|c|}{ 2. Current grade level (mean \pm standard deviation) } & \multirow{2}{*}{$\mathrm{F}$} & \multirow{2}{*}{$\mathrm{P}$} \\
\hline & Freshman $(\mathrm{N}=35)$ & sophomore $(\mathrm{N}=42)$ & Junior $(\mathrm{N}=29)$ & Senior $(\mathrm{N}=55)$ & & \\
\hline I & $3.66 \pm 0.94$ & $3.76 \pm 0.85$ & $3.90 \pm 0.62$ & $3.89 \pm 0.66$ & 0.83 & 0.48 \\
\hline II & $3.89 \pm 0.80$ & $3.74 \pm 0.66$ & $3.66 \pm 0.55$ & $3.67 \pm 0.55$ & 0.97 & 0.41 \\
\hline III & $3.66 \pm 0.87$ & $3.86 \pm 0.65$ & $3.90 \pm 0.62$ & $3.91 \pm 0.65$ & 1.06 & 0.37 \\
\hline IV & $3.29 \pm 0.79$ & $3.50 \pm 0.67$ & $3.48 \pm 0.69$ & $3.49 \pm 0.79$ & 0.71 & 0.55 \\
\hline $\mathrm{V}$ & $2.94 \pm 0.73$ & $3.24 \pm 0.62$ & $3.34 \pm 0.67$ & $3.16 \pm 0.74$ & 2 & 0.12 \\
\hline
\end{tabular}

\subsection{Influence of Performance on Learning Willingness in SPOC Flipped Class}

Table 5 Variance analysis of performance on learning willingness

\begin{tabular}{|c|c|c|c|c|c|c|c|}
\hline & \multicolumn{5}{|c|}{ 3. The current performance levels (mean \pm standard deviation) } & \multirow{2}{*}{$\mathrm{F}$} & \multirow{2}{*}{$\mathrm{P}$} \\
\hline & $85+(\mathrm{N}=15)$ & $80--85(\mathrm{~N}=43)$ & $70--80(\mathrm{~N}=76)$ & $60--70(\mathrm{~N}=26)$ & 6以下 $(\mathrm{N}=1)$ & & \\
\hline I & $4.33 \pm 0.62$ & $3.56 \pm 0.73$ & $3.89 \pm 0.76$ & $3.69 \pm 0.79$ & $3.00 \pm \mathrm{NaN}$ & 3.78 & $0.01^{* *}$ \\
\hline II & $4.53 \pm 0.64$ & $3.86 \pm 0.60$ & $3.68 \pm 0.52$ & $3.23 \pm 0.51$ & $3.00 \pm \mathrm{NaN}$ & 14.31 & $0.00 * *$ \\
\hline III & $4.27 \pm 0.70$ & $3.70 \pm 0.74$ & $3.92 \pm 0.65$ & $3.62 \pm 0.64$ & $3.00 \pm \mathrm{NaN}$ & 3.33 & $0.01 *$ \\
\hline IV & $3.93 \pm 0.80$ & $3.30 \pm 0.64$ & $3.45 \pm 0.76$ & $3.42 \pm 0.76$ & $3.00 \pm \mathrm{NaN}$ & 2.19 & 0.07 \\
\hline $\mathrm{V}$ & $3.60 \pm 0.83$ & $3.07 \pm 0.70$ & $3.21 \pm 0.66$ & $2.96 \pm 0.66$ & $3.00 \pm \mathrm{NaN}$ & 2.37 & 0.06 \\
\hline
\end{tabular}


Since there is only one person below 60 points, the sample is too small to be considered. From the analysis of variance in Table 5, the level of achievement has a significant impact on the support extent for SPOC flipped class and learning awareness. It has a significant impact on the interesting perspectives of SPOC flipped class and whether it will increase learning tasks and whether it will make learning cumbersome has some impact are not significant. Specifically, in terms of supporting attitudes, students with an average score of 85 or above are the most supportive. What's strange is that the 80-85-point student support level is the lowest, but it is still at a relatively high level. In learning self-consciousness, the law of learning is better and more self-conscious, which is consistent with the general understanding. In the problem of whether it is interesting, cumbersome and the task is increased or not, it mainly shows that the higher the score is, the higher the evaluation is, but the 80 points to 85 points are lower than expected.

\subsection{Influence of self-motivated MOOC on learning willingness in SPOC flipped class}

From Table 6, we can see that through data analysis, whether there is an independent MOOC experience has an extremely significant impact on the willingness of SPOC flipped class learning. Specifically, the five aspects are extremely significant, reflecting the higher recognition of online education for students. Students with MOOC experience are more aware of the advantages of online education, and due to the rapid development of MOOC and the school's inclusion of MOOC credits in elective credits, students can continue to select interesting MOOCs and complete them after completing the required credits. The combination of online and offline SPOC flipped class models has a high rating. This reflects that the large-scale promotion of MOOC has a great role in promoting the development of SPOC flipped class in the future.

Table 6 T- test of Self-motivated MOOC on learning willingness

\begin{tabular}{|c|c|c|c|c|}
\hline \multirow{2}{*}{} & $\begin{array}{l}\text { 4. In addition to the electives in the teaching plan, have you ever completed other MOOC } \\
\text { (mean } \pm \text { standard deviation) }\end{array}$ & \multirow{2}{*}{$\mathrm{P}$} \\
\cline { 2 - 5 } & Yes(N=59) & No(N=102) & \\
\hline I & $4.15 \pm 0.74$ & $3.61 \pm 0.72$ & 4.58 & $0.00^{* *}$ \\
\hline II & $3.98 \pm 0.66$ & $3.59 \pm 0.59$ & 3.94 & $0.00^{* *}$ \\
\hline III & $4.19 \pm 0.71$ & $3.64 \pm 0.61$ & 5.19 & $0.00^{* *}$ \\
\hline IV & $3.75 \pm 0.73$ & $3.27 \pm 0.69$ & -4.07 & $0.00^{* *}$ \\
\hline V & $3.41 \pm 0.70$ & $3.03 \pm 0.67$ & -3.36 & $0.00^{* *}$ \\
\hline$* p<0.05^{* *} p<0.01$ & \multicolumn{3}{|l}{} \\
\hline
\end{tabular}

\section{SPOC Flipped Class Design Suggestions}

\subsection{Thought and consciousness level}

Education should be based on educating people and attaching importance to self-development and perfection of human beings. For a long time, teachers have instilled knowledge to students, and students have passively accepted knowledge, which is very harmful to train students' independent consciousness of learning and thinking. In thought, students should understand that they are the subject of learning, to clear their own needs, to study, to explore, to find information for their own difficulties, ask teachers or classmates, and finally overcome them. For teachers, teachers should be clear about their role as "guide" and "helper". Ideological clarity is the premise of SPOC flipped class mode to effectively improve learning quality.

\subsection{Mode construction level}

After the unification of thought, it is how to construct the SPOC flipped class mode concretely. First, teaching resources, teachers can record curriculum videos by themselves, with existing mature MOOC video supplementation, and set a variety of version of the course video to allow students to choose. In the aspect of video length, only one section is described in one video. The length of the video is controlled in the interval of 10 to 30 minutes, and then a large number of model animations are supplemented for students of different learning abilities to choose by themselves after class. Students' learning behavior will be automatically recorded, and they can be selected to make public assessments of these learning 
progresses so as to form a good competition atmosphere. On the other hand, the quality of the offline course is also very important. The engineering curriculum needs a lot of practice. According to the actual demand, the engineering practice and the original experiment courses can be integrated into the whole teaching system in the offline part. When a student completes the course, it investigates the learning effect on the SPOC platform, collects the feedback of the students' suggestions, combines with a large number of learning records on the platform, optimizes all aspects of the SPOC flipped class, and makes full use of the features of the online platform to facilitate the recording and feedback, and constantly improves the teaching quality.

\subsection{Teacher level}

The transformation of SPOC's flipped class is also a challenge for teachers. In addition to the ideological changes, the work content is also very different. Teachers do not have to repeat the contents of the textbooks in a simple and repeated manner, but they need to ensure that they handle the problems left by the students in the discussion area and communicate with each other every day, and pay attention to those students who are seriously behind in the learning process. More importantly, for the characteristics of integration and practicality of engineering education, problem-oriented, it is necessary to design how to make use of the time under the line, so that students can really master knowledge and exercise the ability to solve problems. Teachers need to adapt and learn.

It can be said that SPOC flipped class is a way to improve teaching efficiency. Teachers can free themselves from simple duplicate book knowledge, focus on solving students' difficulties and designing innovative teaching content, which give teachers a larger space to improve teaching quality.

\subsection{Student level}

Different from the traditional classroom, it is the SPOC flipped class that gives students the initiative to choose by themselves. It is with the purpose of improving the efficiency of learning, stimulating students' creativity, and providing personalized development space. Many students may not be able to use the knowledge in university textbooks in the future, but the improvement of their learning ability will benefit them for their whole lives. Many students have problems with learning delays and low motivation. In the SPOC flipped class, the intensity of single-study courses is not high enough. You can read them repeatedly if there are places that you don't understand. With convenient ways to communicate with classmates and teachers, as long as you work hard, you can complete basic learning tasks efficiently. For students who love learning and are interested in further learning and exploration in professional fields, after completing basic learning tasks, they can fully utilize SPOC to reverse the expansion of resources in the classroom, communicate more with teachers and actively participate in various experiments and engineering practices to enhance their learning and professional knowledge.

\section{Acknowledgement}

In this paper, the research was sponsored by the National Social Science Foundation of China (Grant No.17BGL105).

\section{References}

[1]. Wang Zuoli. MOOC: Is a storm of education coming? [J]. China education network. 2013 (4): 10-14. (In Chinese)

[2]. Mcandrew P, Scanlon E. Education. Open learning at a distance: lessons for struggling MOOCs [J]. Science. 2013, 342(6165): 1450-1451.

[3]. Wang X H, Wang J P, Wen F J, et al. Exploration and Practice of Blended Teaching Model Based Flipped Class and SPOC in Higher University [J]. Journal of Education \& Practice. 2016, 7.

[4]. Fox A. From MOOCs to SPOCs [J]. Communications of the Acm. 2013, 56(12): 38-40. 
[5]. Lv Tingting, Wang Na. Based on the SPOC+ digital teaching resource platform, the study of the Overturned Class Teaching Mode - Taking College English as an example [J]. China Educational Technology, 2016 (05): 85-90+131. (In Chinese)

[6]. Zhang Wentong, Dong Wei. Senior Course SPSS Statistical Analysis [Z]. Higher Education Press, 2013. (In Chinese) 